\title{
Evolución clínica y radiológica de una mujer con histiocitosis pulmonar de células de Langerhans durante 18 años
}

\author{
XIMENA CEA B.*, PAULA BUSTOS B.**, \\ ENRIQUE BELLOLIO J.*** y MIGUEL VILLASECA H.****
}

\begin{abstract}
Clinical and radiological evolution of a woman with pulmonary Langerhans cell histiocytosis during 18 years
\end{abstract}

The Pulmonary Langerhans cell histiocytosis (PLCH) is an uncommon pulmonary diffuse cystic disease. This review presents one case of PLCH diagnosed in a non-smoker female adolescent, who consulted for rapidly progressive dyspnea associated to left pleuritic pain that corresponded to a bilateral pneumothorax. The diagnosis was confirmed by surgical biopsy of the lung. Treatment with corticoids (prednisone) was indicated during the first year. After 18 years from diagnosis she presented an important clinical improvement, with a favourable but not complete radiological and spirometric improvement. The cases that make their debut with recurrent spontaneous pneumothorax are infrequent. The natural evolution of this disease is variable and the treatment is still controversial, been the immunosuppressive therapy, as corticoesteroids and cytotoxic agents of limited value, since are few studies that confirm their effectiveness.

Key words: Histiocytosis, Langerhans cells, pneumothorax.

\section{Resumen}

La histiocitosis pulmonar de células de Langerhans (HPCL) es una enfermedad pulmonar difusa quística poco frecuente. En esta revisión, presentamos un caso de HPCL diagnosticada en una adolescente, no fumadora, que consultó por disnea rápidamente progresiva asociada a dolor pleurítico izquierdo, debido a un neumotórax bilateral. El diagnóstico se confirmó por biopsia quirúrgica. Se indicó tratamiento con corticoides (prednisona) durante el primer año. Tras 18 años de seguimiento destaca una importante mejoría clínica, con una evolución radiológica y espirométrica favorable, pero no completa. Los casos que se presentan con neumotórax espontáneo recurrente son raros. La evolución natural de esta enfermedad es variable y su tratamiento aún es controversial, siendo la terapia con inmunosupresores, tal como corticoesteroides y agentes citotóxicos de valor limitado, ya que son escasos los estudios que avalan su eficacia.

Palabras clave: Histiocitosis, células de Langerhan, neumotórax.

\section{Introducción}

Histiocitosis es el término general para indicar algunas enfermedades del sistema monocitomacrófago, que se producen como resultado de la acumulación o proliferación primaria de histio- $\operatorname{citos}^{1}$. La histiocitosis pulmonar de células de Langerhans (HPCL) es una enfermedad intersticial infrecuente que afecta predominantemente a adultos entre la $2^{\mathrm{a}}$ y $4^{\mathrm{a}}$ década de la vida. El compromiso aislado del pulmón se describe sobre el $85 \%$ de los casos, mientras que en el

\footnotetext{
* Médico Broncopulmonar, Depto de Medicina Interna, Universidad de La Frontera.

** Médico cirujano, Hospital de Curacautín.

*** Residente de Anatomía Patológica, Universidad de La Frontera.

**** Anatomo-Patólogo, Jefe Depto Anatomía Patológica, Universidad de La Frontera.
} 
resto de los pacientes se observa compromiso de otros órganos, destacando la médula ósea, el hipotálamo, la piel, los ganglios linfáticos, el hígado y el bazo ${ }^{2,3}$.

$\mathrm{Su}$ incidencia y prevalencia exactas son desconocidas ${ }^{4}$. Sin embargo, se estima una incidencia de 2-5 personas por millón de habitantes por año ${ }^{5}$. La distribución según género es similar, aunque las mujeres presentan un inicio más tardío de la enfermedad. Los caucásicos son afectados con mayor frecuencia que individuos descendientes de africanos o asiáticos ${ }^{6}$.

$\mathrm{Su}$ patogenia es desconocida. No se ha demostrado asociación con predisposición familiar, genética, ocupacional o geográfica. La única asociación conocida es con el hábito tabáquico.

Los síntomas más comunes son: tos no productiva, disnea, dolor pleurítico, fatiga, baja de peso y fiebre. El $25 \%$ de los pacientes son asintomáticos al momento del diagnóstico ${ }^{4}$.

La historia natural de la HPCL es variable. Se describen casos de remisión espontánea de los síntomas hasta pacientes que evolucionan a la fibrosis pulmonar llevando a la insuficiencia respiratoria que puede ser fatal. Su tratamiento aún es controversial y varía de acuerdo a cada pa- ciente. Se han descrito tratamientos con cirugía, radioterapia, corticoides tópicos, quimioterapia o combinaciones entre ellos, y aún, la simple observación ${ }^{8,9}$.

El propósito del presente artículo es describir la presentación y evolución clínica radiológica tras 18 años de seguimiento de una paciente con histiocitosis pulmonar de células de Langerhans.

\section{Caso clínico}

Mujer de 17 años, no fumadora, sin antecedentes mórbidos de relevancia. Consulta por disnea rápidamente progresiva asociada a dolor pleurítico izquierdo. La radiografía de tórax evidenció neumotórax bilateral e infiltrados pulmonares difusos, se instalaron drenajes pleurales bilaterales (Figuras 1 y 2 ). Debido a fístulas broncopulmonares de alto debito no se logra expansión pulmonar por lo que se realizó biopsia quirúrgica a cielo abierto de língula, destacando en el intraoperatorio la presencia de múltiples quistes pulmonares subpleurales. El informe de la biopsia concluyó: granuloma eosinófilo del pulmón (Figuras 3A, 3B y 3C).
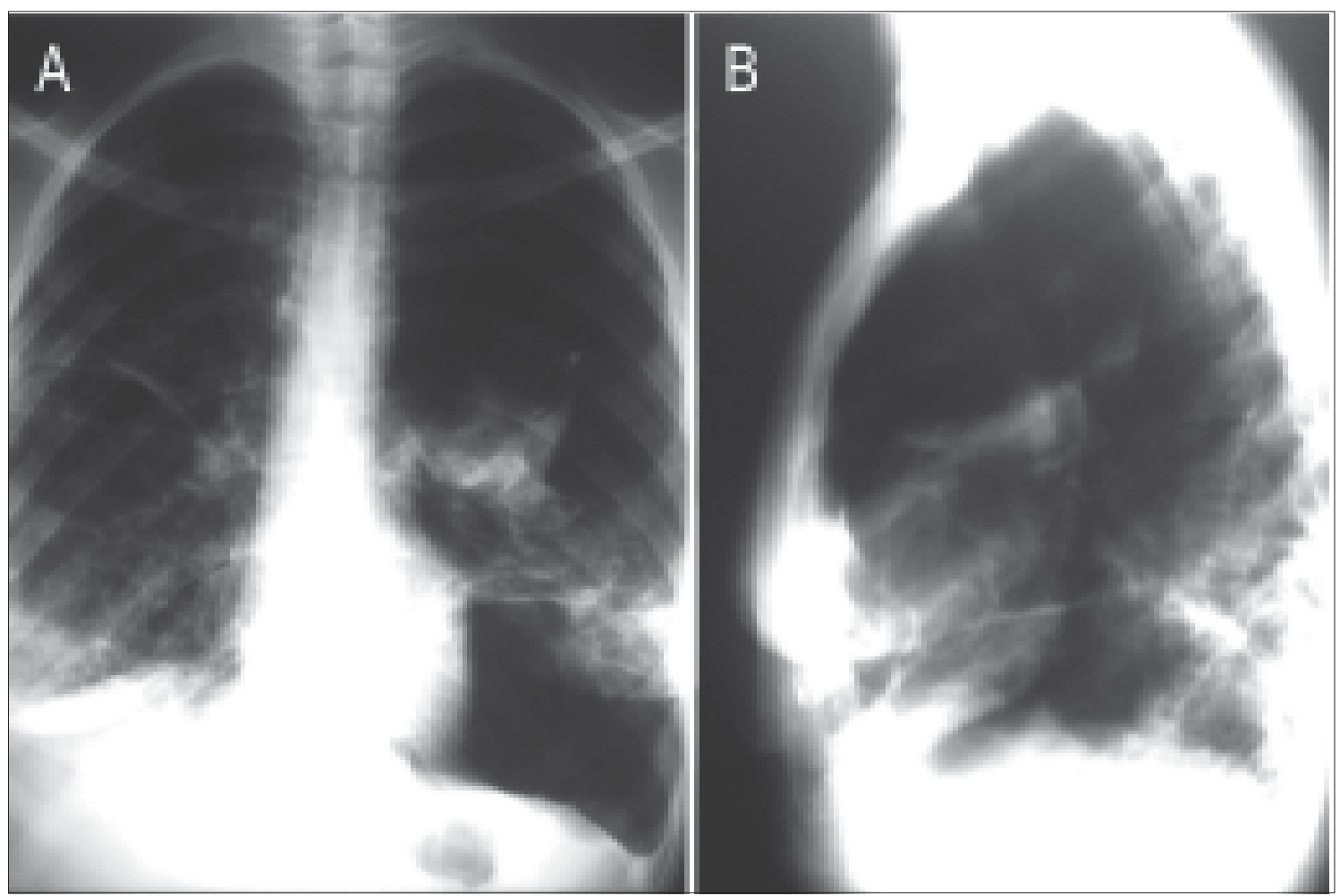

Figura 1. Radiografía de tórax PA y lateral izq. Se observa neumotórax izquierdo. En el hemitórax derecho se aprecian infiltrados reticulonodulares y engrosamiento de la cisura. 


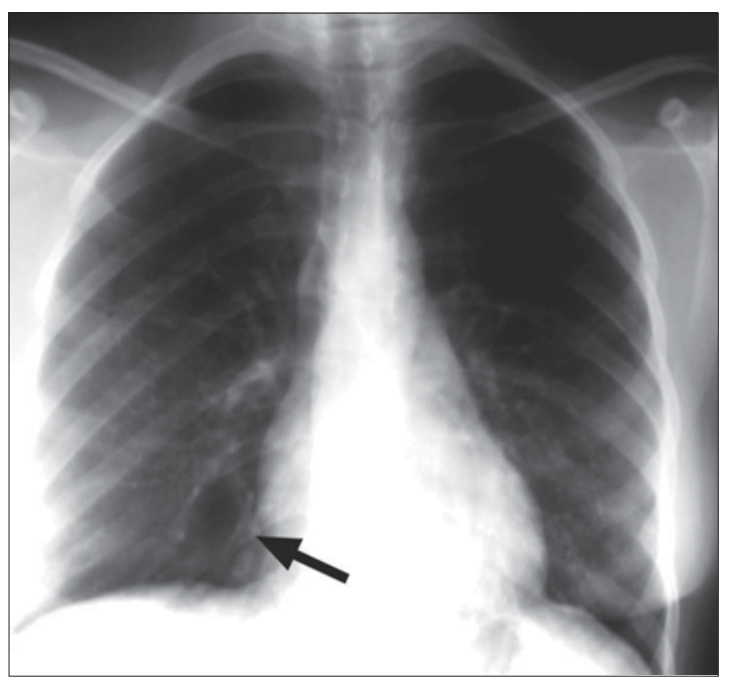

Figura 2. En la radiografía de tórax PA se muestra un infiltrado reticulonodular bilateral y una lesión de aspecto quistico en la zona inferior del pulmón derecho. (flecha).

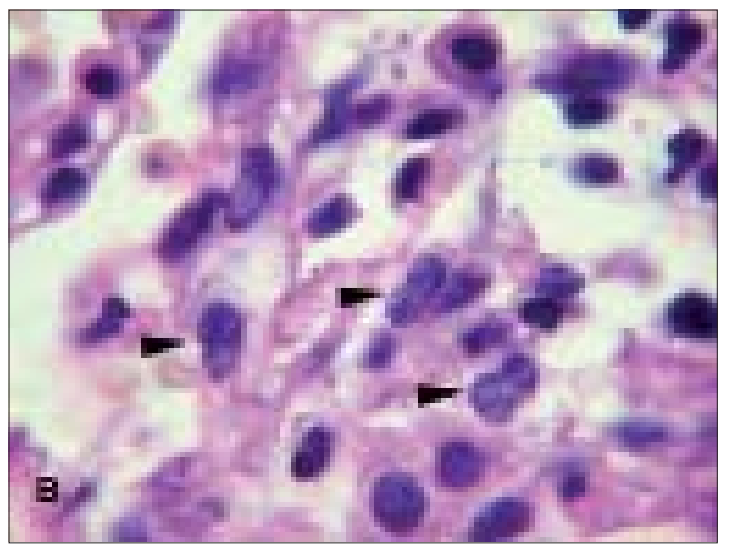

Figura 3B. En la imagen, con lente de inmersión a aumento mayor, se observa que el infiltrado inflamatorio se compone de células (punta de flecha) con citoplasma basófilo pálido y núcleo con escotadura central, característica de histiocitos de Langerhans. (H-E 1000x).

Es nuevamente intervenida quirúrgicamente en dos oportunidades, por fístulas broncopleurales y neumatocele del lóbulo inferior izquierdo de $10 \mathrm{~cm}$ de diámetro. Se realizó resección quirúrgica de la zona comprometida y pleurodesis química con talco.

Posterior a la cirugía cursa con neumonía por Sthaphylococcus aureus, presentando buena respuesta al tratamiento antibiótico. Durante la hospitalización la paciente presenta polidipsia y poliuria de hasta $7.700 \mathrm{ml}$ diarios, sugerente de diabetes insípida.

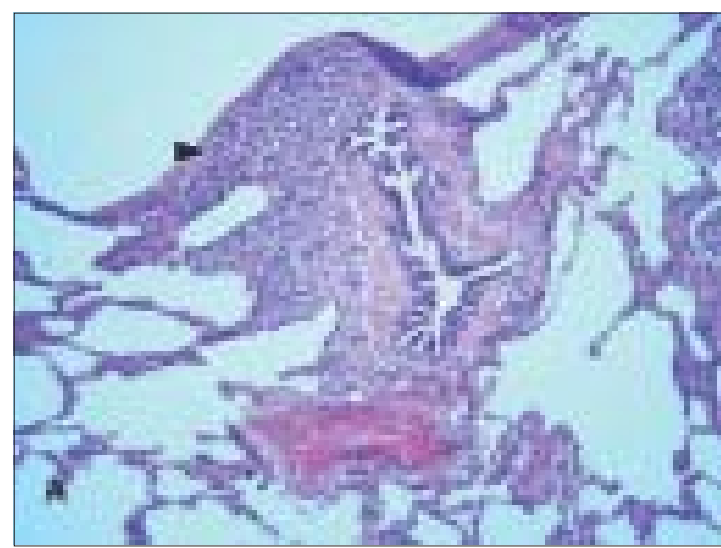

Figura 3A. En la microfotografía se observa tejido pulmonar con infiltrado inflamatorio peribronquiolar (punta de flecha) característico que tiende a tomar una forma estrellada. (H-E 40x).

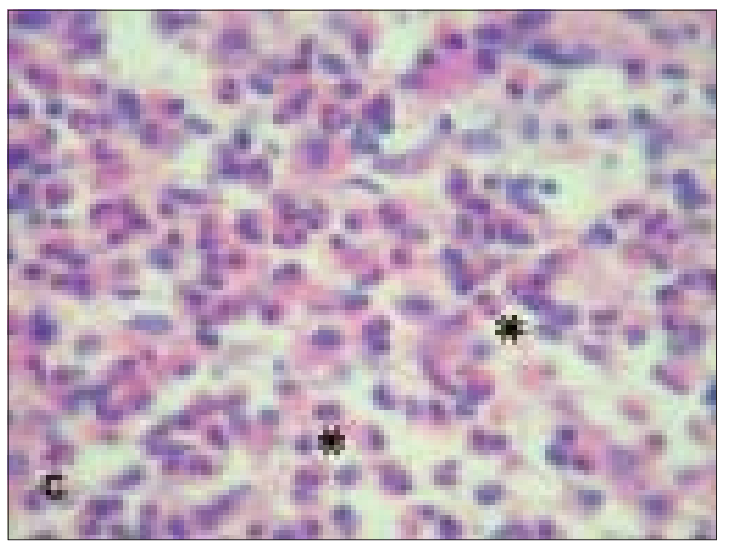

Figura 3C. En la imagen se observa infiltrado inflamatorio con abundantes eosinófilos (asteriscos), los que se pueden observar en la zona central de los nódulos, lo que da el nombre de granuloma eosinófilo. (H-E 400x).

Después de lograr compensar su cuadro infeccioso, comenzó tratamiento con prednisona inicialmente con dosis de $0,5 \mathrm{mg} / \mathrm{kg} / \mathrm{día}$, completando un año de terapia.

Tras 18 años de seguimiento destaca una importante mejoría clínica, siendo actualmente capaz de realizar sus actividades diarias sin inconvenientes. Además con una evolución radiológica favorable importante, persistiendo aún en ambos lóbulos superiores escasos y pequeños espacios aéreos de aspecto quístico en la tomografía axial computada de tórax del año 2006 (Figuras 4 y 5) 


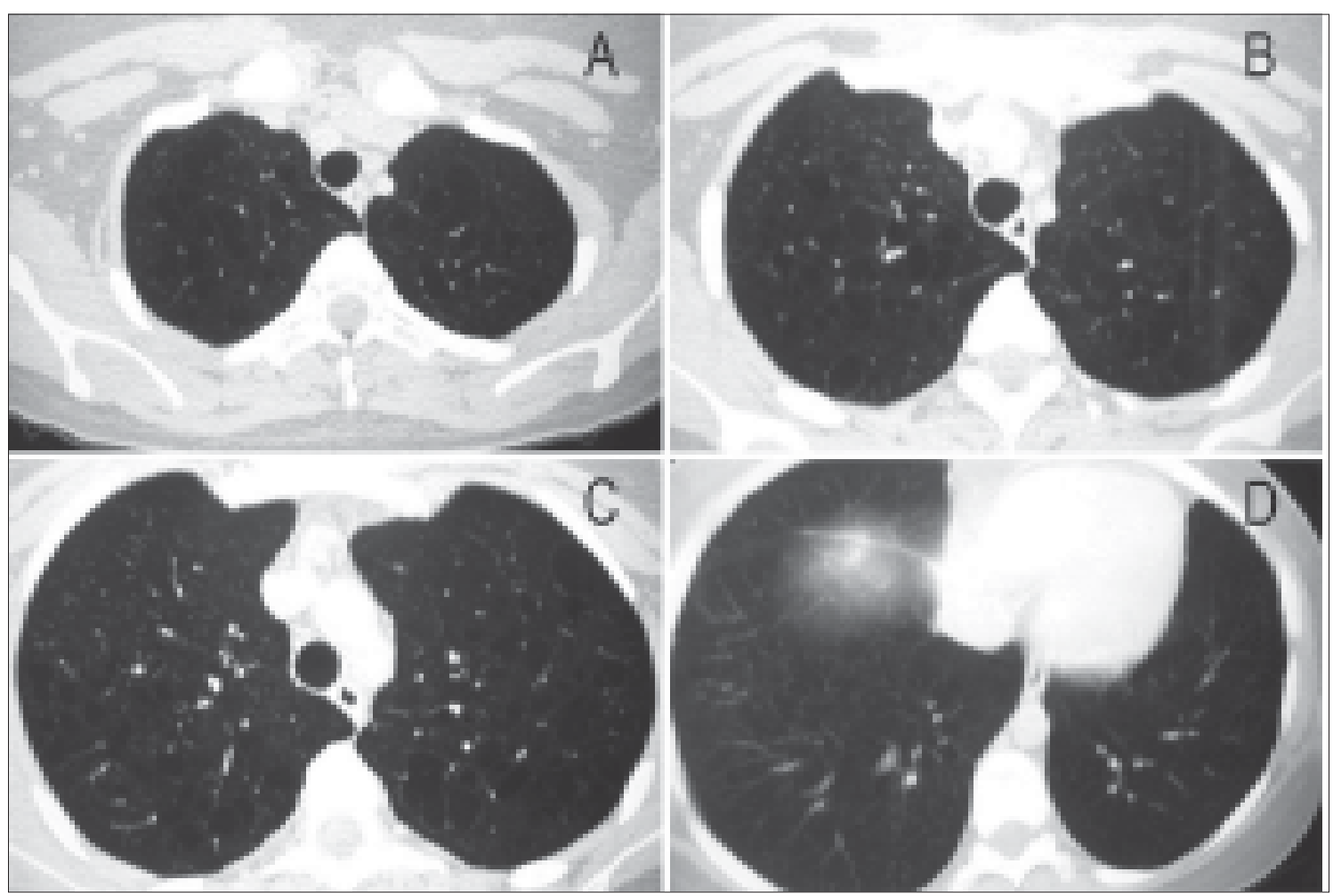

Figura 4. Tomografía computada de tórax (1990). Se observa en ambos campos pulmonares espacios aéreos de aspecto quístico, bien delimitados con paredes finas visibles de diversa amplitud, que afectan predominantemente los lóbulos superiores.

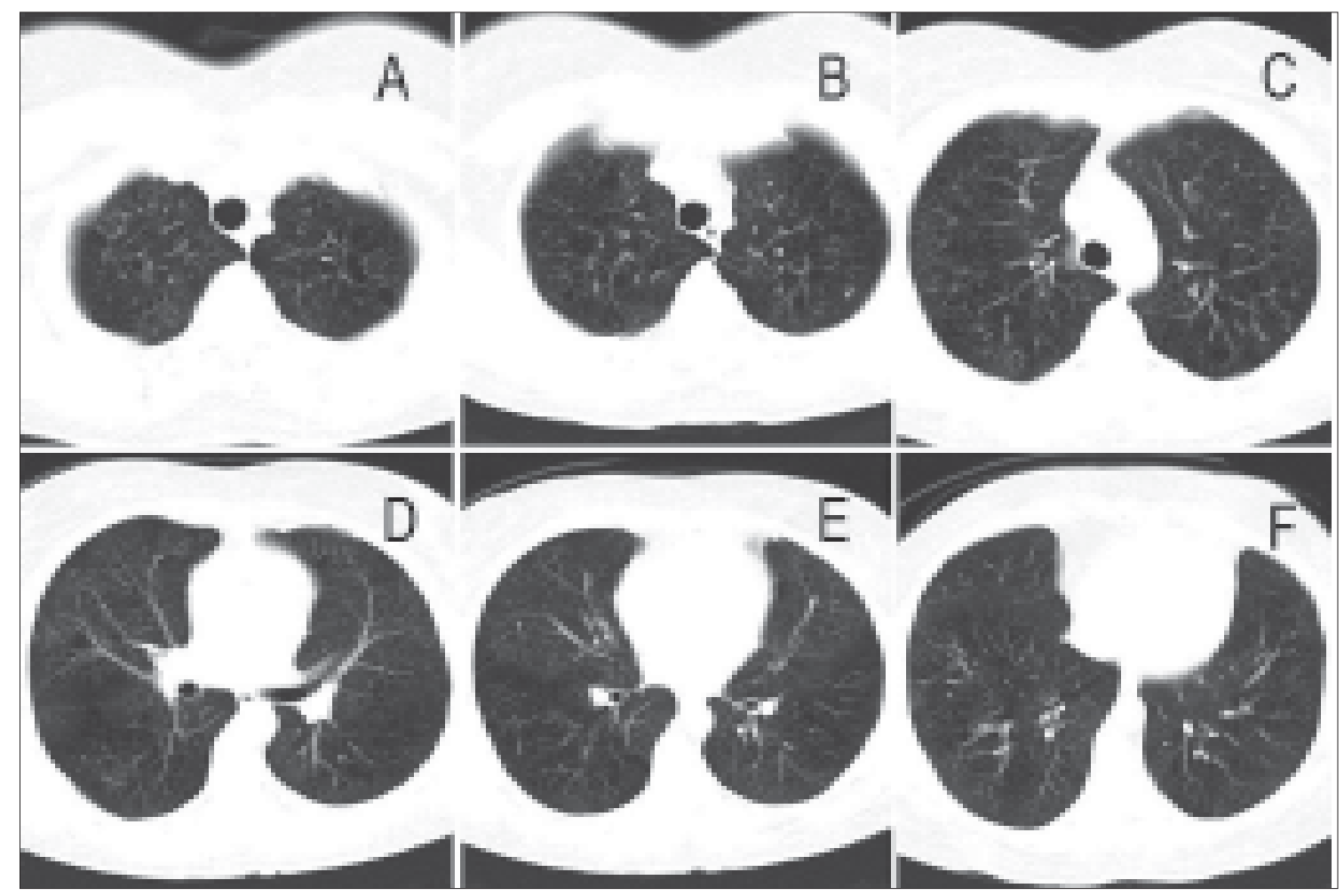

Figura 5. Tomografía computada de tórax (2006). Se observa en la parte superior de ambos lóbulos superiores escasos y pequeños espacios aéreos de aspecto quístico. 
Tabla 1. Evolución de los índices espirométricos

\begin{tabular}{lcccc}
\hline Índices & \multicolumn{2}{c}{ Mar-89 } & \multicolumn{2}{c}{ Sep-06 } \\
espirométricos & Litros & \% & Litros & \% \\
\hline CVF & 1,27 & 38 & 2,15 & 58 \\
$\mathrm{VEF}_{1}$ & 0,98 & 32 & 1,16 & 37 \\
\hline
\end{tabular}

CVF: capacidad vital forzada; $\mathrm{VEF}_{1}$ : Volumen espiratorio forzado durante el primer segundo.

Respecto a los índices espirométricos destaca una mejoría en la $\mathrm{CVF}_{\text {y }} \mathrm{VEF}_{1}$, pero persiste aún un patrón de tipo restrictivo (Tabla 1).

La diabetes insípida se ha controlado efectivamente con carbamazepina e hidroclorotiazida. Actualmente en tratamiento oral con $200 \mathrm{mg}$ al día de carbamazepina y $50 \mathrm{mg}$ al día de hidroclorotiazida.

\section{Discusión}

La enfermedad pulmonar difusa puede ser causada por un gran número de procesos patológicos. El concepto difuso implica el compromiso de todos los lóbulos pulmonares, el cual no es necesariamente uniforme. Una metodología ordenada permite una aproximación acertada en el proceso de diagnóstico, para lo cual se deben considerar tres pilares fundamentales: duración de la enfermedad, patrón radiológico (patrón de las opacidades, distribución y asociación con otros hallazgos radiológicos) y el contexto clínico. En este último se incluye: la edad, el sexo, antecedente de tabaquismo, enfermedades sistémicas previas o actuales, inmunodeficiencia, fármacos, contaminación ambiental o laboral y antecedentes familiares ${ }^{10}$.

La enfermedad pulmonar difusa quística se observa característicamente en linfangioleiomiomatosis pulmonar y en la histiocitosis pulmonar de células de Langerhans. Pero en esta última predomina la alteración en los lóbulos superiores $^{10,11}$.

La célula de Langerhans tiene un citoplasma basófilo y abundante con un núcleo de forma arriñonada. A la microscopía electrónica se evidencian los gránulos de Birbeck, que son estructuras con forma de raqueta. Estas células reaccionan con anticuerpos para la proteína S100 y para la glicoproteína CD1a ${ }^{4}$. En nuestro caso el diagnóstico es presuntivo, ya que se realizó por microscopía de luz, dado que en ese período el hospital de Temuco no contaba con inmunohistoquímica. La estimulación de células de Langerhans por el hábito tabáquico induce la secreción del péptido Bombesina, que estimularía células neuroendocrinas, y éstas a macrófagos alveolares a secretar TNF- $\alpha$, GM-CSF y otras citoquinas resultando en la proliferación de fibroblastos, que finalmente causan la fibrosis y la formación de nódulos inflamatorios ${ }^{3}$. Se reporta que sobre el $90 \%$ de los pacientes con HPCL son fumadores, en este caso la paciente no presentaba este antecedente.

Generalmente, los pacientes se diagnostican en una de las siguientes situaciones: como un hallazgo incidental en la radiografía de tórax, posterior a un neumotórax espontáneo y por síntomas respiratorios o constitucionales, especialmente fiebre o baja de peso ${ }^{12,13}$. Son generalmente reportes aislados los pacientes que presentan como primera manifestación clínica un neumotórax, como en el caso descrito ${ }^{14,15}$. Este resulta de la rotura de lesiones quísticas subpleurales o por destrucción de la pleura por la formación de granulomas adyacentes ${ }^{16}$.

Los síntomas y signos de HPCL son inespecíficos. Cuando los pacientes presentan síntomas, los más comunes son tos seca y disnea (Tabla 2).

El neumotórax espontáneo recurrente se presenta en el 15 a $25 \%$ de los pacientes ${ }^{20}$. La diabetes insípida secundaria al compromiso hipotalámico es reportada en el 15\% de los pacientes. Este último conlleva un peor pronóstico de la enfermedad ${ }^{6}$.

El examen pulmonar es generalmente normal, aunque pueden existir crepitaciones, dependiendo del estado evolutivo de la enfermedad y el grado de fibrosis ${ }^{4}$.

En etapas iniciales de la enfermedad los exámenes más sensibles son los gases en sangre arterial en reposo y/o durante el ejercicio y la difusión del monóxido de carbono. La disminución de la capacidad de difusión del monóxido

Tabla 2. Principales manifestaciones clínicas de la histiocistosis pulmonar de células de Langerhans $^{12,17-14}$

\begin{tabular}{lr}
\hline Clínica & \multicolumn{1}{c}{} \\
\hline Tos no productiva & $56-70$ \\
Disnea & $40-87$ \\
Dolor pleurítico & $10-21$ \\
Fatiga & 30 \\
Baja de peso & $20-30$ \\
Fiebre & 15 \\
\hline
\end{tabular}


de carbono se presenta en el 70-90\% de los casos $^{4}$.

Característicamente los exámenes de función pulmonar muestran un patrón restrictivo. El patrón obstructivo es infrecuente, pero puede presentarse en la linfangioleiomiomatosis, HPCL, sarcoidosis y neumonitis por hipersensibilidad ${ }^{10}$.

La radiografía de tórax es el primer método de detección de una enfermedad pulmonar difusa. Su alteración puede ser muy característica, pero no es diagnostica. Una combinación de las características siguientes es altamente específica para HPCL: nódulos mal definidos o radiados de 2 a 10 milímetros de diámetro, infiltrados reticulonodulares, imagen en panal de abeja en zonas superiores y medias, volumen pulmonar conservado y ángulos costofrénicos libres ${ }^{21-22}$. Pero en el $10 \%$ de los pacientes este examen puede no estar alterado, sobre todo en el inicio de la enfermedad. Se debe mencionar que al analizar el patrón de las opacidades en la radiografía de tórax se pueden interpretar de forma diferente cuando se compara con el patrón en la tomografía computada de alta resolución, debido a que este último examen proporciona imágenes en tres dimensiones ${ }^{10}$.

En la tomografía computada de alta resolución (TCAR) de tórax lo más frecuente de encontrar son lesiones quísticas menores de 10 $\mathrm{mm}$ de diámetro con pared fina, menor o igual a $1 \mathrm{~mm}$ de grosor. Los quistes son más irregulares y complejos en comparación con la linfangioleiomiomatosis $^{4-11}$. Otra utilidad de este examen es ayudar a seleccionar el sitio más apropiado para la biopsia pulmonar.

El diagnóstico definitivo es realizado por biopsia pulmonar, idealmente obtenida por cirugía a cielo abierto o por videotoracoscopía, la que tiene un mejor rendimiento al compararla con la biopsia endoscópica debido a la menor cantidad de tejido que se obtiene para estudio y a la distribución parcelar de esta enfermedad. Debido a su baja incidencia y alta tasa de remisión espontánea no hay estudios que comparen los diferentes tratamientos en adultos con HPCL. La medida inicial de cualquier régimen de tratamiento es el cese del hábito tabáquico ${ }^{23}$. Con esta medida se consigue una estabilización e incluso una desaparición de los síntomas en la mayoría de los pacientes ${ }^{4}$. Pero también se describen casos de algunos pacientes que han evolucionado a una remisión clínica e imagenológica completa o parcial independiente del cese del hábito tabáquico.

La terapia con inmunosupresores, tal como corticoesteroides y agentes citotóxicos son de valor limitado, ya que son escasos los estudios que avalan su eficacia. Se describe que sólo pacientes con opacidades nodulares importantes responden al tratamiento con corticoesteroides ${ }^{6}$. Se recomienda el tratamiento durante un año con dosis de $0,5-1 \mathrm{mg} / \mathrm{kg} /$ día de prednisona o dosis equivalente de otros glucocorticoides ${ }^{24}$. Para enfermedad progresiva refractaria a los corticoides o en casos de enfermedad multisistémica se han usado agentes quimioterápicos como vinblastina, metotrexato o ciclofosfamida.

El trasplante pulmonar debe ser considerado en pacientes con enfermedad avanzada, que presenten insuficiencia respiratoria grave y en casos de hipertensión pulmonar severa ${ }^{4-6}$, debido a que se describe la recurrencia en el pulmón trasplantado.

Se recomienda el seguimiento a largo plazo de todos los pacientes con HPCL, aún después de una estabilización clínica aparente, por la posibilidad de progresión o recurrencia de la enfermedad. Se describe que aún logrando una remisión de las lesiones radiológicas, en algunos pacientes se mantiene alterada la función pulmonar.

En una revisión de la Clínica Mayo de 102 pacientes adultos con HPCL la media de sobrevida fue de 12,5 años desde el diagnóstico. La tasa estimada de sobrevida a los 5 y 10 años fue de 74 y $64 \%$ respectivamente. El $50 \%$ de las muertes que ocurrieron durante el período de seguimiento fue debido a falla respiratoria. La segunda causa de fallecimiento fueron las neoplasias, principalmente de origen hematológico o epitelial ${ }^{7}$.

En conclusión, este caso clínico ilustra los hallazgos clínicos, radiológicos y de función pulmonar característicos de esta enfermedad. Pero debido a su baja prevalencia e incidencia es difícil evaluar su evolución natural y la efectividad de las diferentes terapias disponibles en la actualidad.

\section{Bibliografía}

1.- MUNN S, CHU A C. Langerhans cell histiocytosis of the skin. Hematol Oncol Clin North Am 1998; 12: 269-86.

2.- VIDERAGAY F, MARTÍNEZ M, MALDONADO P, ZULAICA H, VÁZQUEZ E. Histiocitosis de células de Langerhans. Ann Med Asoc Med Hosp ABD 2002; 47: 38-43.

3.- VASSALLO R, RYU J H, COLBY TV, HARTMAN T, LIMPER A H. Pulmonary Langerhans'-cell histiocytosis. N Engl J Med 2000; 342: 1969-78.

4.- GARCÍA BERNÁRDEZ A M, ÁLVAREZ CUESTA C C, RIVAS CARMENADO M E, VALLINA ÁLVAREZ E, ARRIBAS CASTRILLO J M. Histiocitosis pulmonar 
de células de Langerhans. An Med Interna (Madrid). 2006; 23: 73-6.

5.- KIM C K, PARK C B, JIN U, SEO E J. Pulmonary Langerhans' cell histiocytosis presented with recurrent pneumothorax. Interact Cardiovasc Thorac Surg 2006; 5: 512-3.

6.- CRAUSMAN R S, KING T E. Pulmonary Langerhans cell histiocytosis. UpToDate. 2007 April. Version 15.2.

7.- VASSALLO R, RYU J H, SCHROEDER D R, DECKER P A, LIMPER A H. Clinical outcomes of pulmonary Langerhans'-cell histiocytosis in adults. N Engl J Med 2002; 346: 484-90.

8.- COUSElO J, LÓPEZ M, COUCE M, FUSTER M. Histiocitosis X en la infancia. Rev Esp Pediatr 1987; 43: $15-22$.

9.- ARICÒ M, EGELER R M. Clinical aspects of Langerhans cell histiocytosis. Hematol Oncol Clin North Am 1998; 12: 247-58.

10.- RYU J H, OLSON E J, MIDTHUN D E, SWENSEN S J. Diagnostic Approach to the Patient with Diffuse Lung Disease. Mayo Clinic Proc 2002; 77: 1221-7.

11.- RYU J H, SWENSEN S J. Cystic and Cavitary Lung Diseases: Focal and Diffuse. Mayo Clin Proc 2003; 78: 744-52.

12.- BASSET F, CORRIN B, SPENCER H, LACRONIQUE J, ROTH C, SOLER P, et al. Pulmonary histiocytosis X. Am Rev Respir Dis 1978; 118: 811-20.

13.- VASSALLO R, LIMPER A H. Pulmonary Langerhans' cell histiocytosis. Semin Respir Crit Care Med 2002; 23: 93-101.

14.- ARENS R, KRAMER S S. Images in clinical medicine. Pulmonary Langerhans'-cell granulomatosis (histiocytosis X). N Engl J Med 2000; 342: 1959.

15.- BADRA F A, KARAMOUZIS M V, ZOLOTA V, PASTROMAS V. A case of multiorgan Langerhans' cell histiocytosis presented with pneumothorax. Eur J Intern Med 2004; 15: 467-9.

16.- KRAWCZYK P, CZEKAJSKA-CHEHAB E, KIESZKO
R, SIWIEC J, WEGRZYN-SZKUTNIK I, GRYGLICKA

$\mathrm{B}$, et al. Difficulties in the diagnosis of rare immunological diseases manifesting with cystic lung disease and spontaneous pneumothorax: Case reports. Heart Lung 2004; 33: 21-5.

17.- SUNDAR K M, GOSSELIN M V, CHUNG H L, CAHILL B C. Pulmonary Langerhans cell histiocytosis: emerging concepts in pathobiology, radiology, and clinical evolution of disease. Chest 2003; 123: 1673-83.

18.- MARCY T W, REYNOLDS H Y. Pulmonary histiocytosis X. Lung 1985; 163: 129-50.

19.- CRAUSMAN R S, JENNINGS C A, TUDER R M, ACKERSON L M, IRVIN C G, KING T E Jr. Pulmonary histiocytosis $\mathrm{X}$ : pulmonary function and exercise pathophysiology. Am J Respir Crit Care Med 1996; 153: 426-35.

20.- MÉNDEZ J L, NADROUS H F, VASSALLO R, DECKER P A, RYU J H. Pneumothorax in pulmonary Langerhans cell histiocytosis. Chest 2004; 125: 102832.

21.- AGUAYO S M, SCHWARZ M I, MORTENSON R L. The role of the chest radiograph in the evaluation of disease severity and clinical course in eosinophilic granuloma. Am Rev Respir Dis 1990; 141: A61.

22.- LACRONIQUE J, ROTH C, BATTESTI J P, BASSET F, CHRETIEN J. Chest radiological features of pulmonary histiocytosis $\mathrm{X}$ : a report based on 50 adult cases. Thorax 1982; 37: 104-9.

23.- MOGULKOC N, VERAL A, BISHOP P W, BAYINDIR U, PICKERING C A, EGAN J J. Pulmonary Langerhans' cell histiocytosis: radiologic resolution following smoking cessation. Chest 1999; 115: 1452-5.

24.- ABELLÁN MARTÍNEZ M C, MÉNDEZ MARTÍNEZ P, SÁNCHEZ GASCÓN F, HERNÁNDEZ MARTÍNEZ J, SÁNCHEZ MONTÓN T, ROMERO MAS E. Pulmonary histiocytosis X. Report of a case and review of the literature. An Med Interna 2002; 19: 16-8.
Correspondencia a:

Dra. Paula Andrea Bustos Barahona

Hospital de Curacautín

Servicio Salud Araucanía Norte

Serrano s/n, Curacautín

E-mail: bustos81@yahoo.com 